\title{
Differential scanning calorimetric study of solidification behavior of monoacylglycerols to investigate the cold-flow properties of biodiesel
}

\section{$\operatorname{AUTHOR}(\mathrm{S})$ :}

Seniorita, Latifa; Minami, Eiji; Yazawa, Yoshiteru; Hitoshi, Hayashi; Saka, Shiro

\section{CITATION:}

Seniorita, Latifa ...[et al]. Differential scanning calorimetric study of solidification behavior of monoacylglycerols to investigate the cold-flow properties of biodiesel. Journal of the American Oil Chemists' Society 2019, 96(9): 979-987

\section{ISSUE DATE:}

2019-09

\section{URL:}

http://hdl.handle.net/2433/250161

\section{RIGHT:}

This is the peer reviewed version of the following article: Seniorita, L., Minami, E., Yazawa, Y., Hayashi, H. and Saka, S. (2019), Differential Scanning Calorimetric Study of Solidification Behavior of Monoacylglycerols to Investigate the Cold - Flow Properties of Biodiesel. J Am Oil Chem Soc, 96: 979-987, which has been published in final form at https://doi.org/10.1002/aocs.12267. This article may be used for non-commercial purposes in accordance with Wiley Terms and Conditions for Use of Self-Archived Versions.; The full-text file will be made open to the public on 25 July 2020 in accordance with publisher's 'Terms and Conditions for Self-Archiving'.; This is not the published version. Please cite only the published version.; この論文は出版社版でありません。引用の際には出版社版をご確認ご利用ください。 
Title: Differential scanning calorimetric study of solidification behavior of monoglycerides to investigate cold-flow properties of biodiesel

Running title: Thermodynamics of binary monoglycerides

Authors: Latifa Seniorita ${ }^{1}$, Eiji Minami ${ }^{1}$, Yoshiteru Yazawa ${ }^{2}$, Hitoshi Hayashi ${ }^{2}$, Shiro Saka ${ }^{1}$

\section{Affiliations:}

1. Graduate School of Energy Science, Kyoto University, Japan

2. Material Engineering Division No.2, Toyota Motor Corporation, Japan

Corresponding author: Eiji Minami

Address: Graduate School of Energy Science, Kyoto University, Yoshida-honmachi, Sakyo-ku, Kyoto 606-8501, Japan

Tel/Fax: +81 (0)75 7535713

E-mail: minami@energy.kyoto-u.ac.jp 


\section{Abstract:}

2 Monoglycerides (MGs) are impurities present in biodiesel as a result of incomplete reactions.

3 MGs often solidify in biodiesel even at room temperature because of their high melting

4 points. This worsens the cold-flow properties such as the cloud point and pour point. We

5 hypothesized that several types of MGs solidify simultaneously; therefore we performed

6 differential scanning calorimetry of binary mixtures of MGs to elucidate their interactions

7 during solidification. Three thermodynamic formulas were then applied to the experimental

8 results: 1) non-solid-solution, 2) solid-solution, and 3) compound formation models. Binary

9 mixtures of MGs showed complicated liquidus curves with multiple upward convex shapes,

10 with which only the compound formation model fitted well. This model was applied to

11 multi-component mixtures that consisted of MGs and fatty acid methyl esters as surrogate

12 biodiesel fuels. We confirmed that the model still worked well. The results show that the

13 compound formation model has good potential for predicting the cold-flow properties of

14 biodiesel.

16 Keywords: Biodiesel, Polymorphism, Thermal analysis 
Introduction

transesterification of plant oils, and is used as a fossil diesel substitute. It is renewable and

has a low sulfur content but poor cold-flow properties (CFPs) compared with those of fossil

diesel. The CFPs such as the cloud point and pour point determine the low-temperature

fluidity of a liquid fuel. Prediction of biodiesel CFPs is therefore important for minimizing the risk of fuel clogging.

Many models for predicting biodiesel CFPs have been reported (Imahara et al.,

2006; Lopes et al., 2008; Sarin et al., 2009; Coutinho et al., 2010; Dunn, 2010). Saturated

FAMEs such as methyl palmitate greatly affect the CFPs because of their high melting points

(Dunn and Bagby, 1995; Knothe, 2005). Sarin et al. (2009) established regression formulas

for predicting the cloud point and pour point as a linear function of methyl palmitate content

for biodiesel fuels from palm (Elaeis guineensis), jatropha (Jatropha curcas), and pongamia (Pongamia pinnata) oils. Such empirical models are simple and easy to use, but not applicable to biodiesel fuels from other feedstocks because the fatty acid compositions are different. Some research groups have investigated thermodynamic models that are applicable to any biodiesel (Imahara et al., 2006; Lopes et al., 2008; Coutinho et al., 2010). Imahara et al. (2006) calculated the solid-liquid equilibria of FAME mixtures, with the assumption of 
agreement with the experimental cloud points. The liquidus temperature is defined as the temperature above which a given mixture is completely in the liquid phase. A solid phase can form when the mixture is cooled below the liquidus temperature, therefore it is an important index for predicting CFPs. 2010) were based on the theory of solid-liquid equilibrium, where the fugacity of each component is equal in solid and liquid phases. This theory expresses the relationship between the liquidus temperature and properties of the mixture, such as chemical composition, melting point and enthalpy of fusion of each component. The liquidus temperature is thus predicted from the properties of the mixture. The theory is well described in a textbook of chemical physics (Smith et al., 2005). The presence of minor components also considerably affects the CFPs.

51 Monoglycerides (MGs), which are intermediate compounds produced during transesterification, are typical minor components in biodiesel, and the European standard restricts the total amount of MGs to below $0.8 \mathrm{wt} \%$ (Committee for Standardization Automatic Fuels, 2008). MGs occasionally solidify even at around room temperature because their melting points are high (Tang et al., 2008; Chupka et al., 2011; Chupka et al., 2014). MGs have various crystalline structures, namely $\alpha, \beta^{\prime}$, and $\beta$ types, and each has a different melting point in the following order, $\alpha<\beta^{\prime}<\beta$ (Fischer et al., 1920; Malkin and Shurbagy, 
58

60

63

1936). In general, $\alpha$-type crystals form first when a liquid MG is cooled until the phase transition occurs. The $\alpha$ crystals are converted irreversibly to the $\beta^{\prime}$ type and then to the $\beta$ type after specific transition times (Maruyama et al., 1973). The potential presence of several polymorphs makes the solidification behavior of MGs complicated. Chupka et al. studied the effects of MGs on biodiesel CFPs and highlighted the importance of MG polymorphism (Chupka et al., 2011; Chupka et al., 2014).

Our research group previously developed a thermodynamic model for calculating the solid-liquid equilibria of surrogate biodiesel fuels containing MGs (Yoshidomi et al., 2017; Sugami et al., 2017). We found that a binary mixture of a MG and a FAME behaves as a non-ideal liquid solution because of the large difference between the chemical structures of the components, and the non-ideality is well described by a modified version of the universal quasi-chemical functional-group activity coefficients (UNIFAC) model, known as the UNIFAC (Dortmund) model (Gmehling et al., 1993). When the mixture contains only one type of MG, the predicted values are in excellent agreement with the experimental results. However, deviations arise when the mixture includes two different MGs (Yoshidomi et al., 2017; Sugami et al., 2017). We hypothesized that this discrepancy is caused by co-crystallization (solid solution) of the different MGs, because our previous model assumed that the solid phase consists of a single component. Lutton and Jackson (1967) and Maruyama et al. (1978) have reported the formation of such solid solutions of different MGs 
77 under certain conditions.

79 investigate the interactions between MGs and to develop an appropriate thermodynamic

80 model for describing the solidification behaviors of MGs. The model obtained was then

81 applied to multi-component mixtures, which contained two types of MGs in FAMEs and

82 served as surrogate biodiesel fuels. The results of this study will help to establish a

83 prediction model for real biodiesel, which contains several types of MGs.

84

\section{Experimental Procedures}

86 Materials

The MG samples used were 1-monolaurin (MG12:0, purity 99\%, Tokyo Chemical

Industry, Tokyo, Japan), 1-monopalmitin (MG16:0, 99\%, Olbracht Serdary Research

Laboratories (OSRL), Toronto, Canada), and 1-monostearin (MG18:0, 99\%, OSRL). The

FAME samples were methyl laurate (FAME12:0, 99\%), methyl palmitate (FAME16:0, 99.5\%),

and methyl oleate (FAME18:1, 99\%), which were all purchased from Sigma-Aldrich Japan,

without purification. 
96

98

99

100

101

103

111 be sufficient. After removal from the chamber, the sample was exposed at room temperature Analytical methods

For DSC analyses, samples (about $10 \mathrm{mg}$ ) were placed in non-hermetic aluminum-based pans under a dry nitrogen flow. Indium and zinc were used for temperature calibration and $\alpha$-alumina was used as a reference material. We determined the liquidus temperature for each sample from the obtained DSC profile. Because MGs are polymorphic, we used two different methods for examining $\alpha$ - and $\beta$-type crystals.

For $\alpha$-type crystals, each sample was heated until fully melted and cooled until the first exothermic peak was detected; the solid phase formed at this time is thought to consist of $\alpha$-type crystals (Maruyama et al., 1973; Yoshidomi et al., 2017). The sample was then reheated immediately at a heating rate of $3{ }^{\circ} \mathrm{C} / \mathrm{min}$ and the DSC profile was recorded. This rapid heating prevents the crystal transition to the $\beta^{\prime}$ or $\beta$ type during analysis. For $\beta$-type crystals, each solidified sample was held in a thermostatic chamber at $50{ }^{\circ} \mathrm{C}$ for four weeks to ensure the transition to the $\beta$ type, which is the most stable structure. The reported times for transition to the $\beta$ type are about $0.1,100$, and $230 \mathrm{~h}$ at $50{ }^{\circ} \mathrm{C}$ for MG12:0, MG16:0, and MG18:0, respectively (Maruyama et al., 1971); four weeks (672 h) is therefore considered to for a few minutes, and then DSC was performed at a heating rate of $1{ }^{\circ} \mathrm{C} / \mathrm{min}$. For each pure MG, the melting point was estimated from the onset temperature of the endothermic peak in the DSC profile. In the case of a binary or multi-component mixture, 
115 the highest endothermic peak maximum temperature was defined as the experimental liquidus

116 temperature, as in previous studies (Maruyama et al., 1971; Knothe and Dunn, 2009;

117 Yoshidomi et al., 2017). Note that this is a rough estimate because the absolute liquidus

118 temperature is generally difficult to determine, especially for multi-component systems.

120 Thermodynamic models

Three thermodynamic models were used to calculate the liquidus temperatures. The

122 first two models were based on the solid-liquid equilibrium and the third was derived from

123 the reaction equilibrium. The calculations were conducted using programs coded with

124 Microsoft Visual Basic for Applications on Excel.

Solid-liquid equilibrium

At solid-liquid equilibrium, the fugacity of each component $i$ in a given system is

128 the same in the solid (S) and liquid (L) phases; this relationship is expressed by the following

129 equation:

$$
\gamma_{i}^{\mathrm{L}} x_{i} f_{i}^{\mathrm{L}}=\gamma_{i}^{\mathrm{S}} z_{i} f_{i}^{\mathrm{S}}
$$

where $x_{i}$ and $z_{i}$ are the mole fractions of component $i$ in the liquid and solid phases, 
$134\left(T_{\mathrm{m}, i}\right)$ and enthalpy of fusion $\left(\Delta H_{\mathrm{m}, i}\right)$ of the pure component $i$ as follows (Smith et al, 2005):

$$
\frac{\gamma_{i}{ }^{\mathrm{L}} x_{i}}{\gamma_{i}^{\mathrm{S}} z_{i}}=\frac{f_{i}^{\mathrm{S}}}{f_{i}^{\mathrm{L}}}=\exp \frac{\Delta H_{m, i}}{R T_{m, i}}\left(\frac{T-T_{m, i}}{T}\right)
$$

136 Two assumptions were made when using equation (2) to calculate the liquidus temperature $T$

137 of a given mixture. The first, which was used in the non-solid-solution model, is that the

138 solid phase consists of a single component $\left(z_{i}=1\right.$, therefore $\left.\gamma_{i}^{\mathrm{S}}=1\right)$. This means that

139 different MGs are immiscible in the solid phase. For a binary mixture, the relationship

140 between the mole fraction and liquidus temperature is given by

The second assumption, which was used in the solid-solution model, is that different

143 MGs can form a continuous solid solution $\left(z_{i} \neq 1\right)$ but the solution is ideal $\left(\gamma_{i}^{\mathrm{S}}=1\right)$. In this

144 case, the liquidus temperature can be determined from the following equation:

$$
\left[\gamma_{1}{ }^{\mathrm{L}} x_{1} / \exp \frac{\Delta H_{m, 1}}{R T_{m, 1}}\left(\frac{T-T_{m, 1}}{T}\right)\right]+\left[\gamma_{2}{ }^{\mathrm{L}} x_{2} / \exp \frac{\Delta H_{m, 2}}{R T_{m, 2}}\left(\frac{T-T_{m, 2}}{T}\right)\right]=1
$$

This is derived from equation (2) and $z_{1}+z_{2}=1$. For both models, the activity coefficients in

147 the liquid phase, $\gamma_{i}^{\mathrm{L}}$, were calculated using the UNIFAC (Dortmund) model (Gmehling et al,

148 1993), as in our previous studies (Yoshidomi et al, 2017; Sugami et al, 2017).

Reaction equilibrium

This model assumes that the solidification of MGs is similar to a chemical reaction. 
153

155

157 where $\gamma_{i}^{\mathrm{L}}$ and $x_{i}$ are the activity coefficient and mole fraction of component $\mathrm{C}_{i}$ in the liquid

158 phase, respectively. The term $z_{3}$ is the mole fraction of compound $\mathrm{C}_{3}$ in the solid phase, but

159 because no other solid is present in the system, it can be assumed to be unity. However, there

160 is another expression for the equilibrium constant $K_{\mathrm{a}}$, which is derived from the Gibbsthe UNIFAC (Dortmund) model.

$$
K_{a}=K_{\mathrm{ref}} \times \exp \frac{\Delta H_{\mathrm{ref}}}{R T_{\mathrm{ref}}}\left(\frac{T-T_{\mathrm{ref}}}{T}\right)
$$

where $K_{\text {ref }}$ and $\Delta H_{\text {ref }}$ are the equilibrium constant and enthalpy of reaction, respectively, at an arbitrarily chosen reference temperature $T_{\text {ref. }}$ By combining equations (6) and (7), we can determine the liquidus temperature $T$. This model was built according to the method reported by Tumakaka et al. (2007) and is referred to as the compound formation model. The detailed calculation procedure will be described in the following section. It should be noted that $v_{1}$ and $v_{2}$ can be used as fitting parameters in this model. The $\gamma_{i}{ }^{\mathrm{L}}$ terms were estimated by using 


\section{Results and Discussion}

173

Pure component properties

174

All three thermodynamic models involve pure component properties: the melting

175

point $T_{\mathrm{m}}$ and enthalpy of fusion $\Delta H_{\mathrm{m}}$. We therefore used DSC to determine these properties

176 for each pure MG and all crystalline forms; the results are shown in Table 1. We measured

177 three times for each component and chose the middle value. The error ranges were $-0.7 \sim$

$178+1.2{ }^{\circ} \mathrm{C}$ for melting point and $-14 \sim+10 \%$ for enthalpy. The relatively large error for enthalpy

179 might be because of the measurement error of the sample weight (only $10 \mathrm{mg}$ ). However, this

180 error did not critically affect the calculation results.

Maruyama et al., 1971; Yoshidomi et al., 2017), therefore we used them for performing

are also shown in Table 1; they were used to estimate the activity coefficients $\gamma_{i}^{\mathrm{L}}$ with the

UNIFAC (Dortmund) model.

186

Binary MG behaviors

Various binary mixtures were analyzed by DSC. Figure 1 shows DSC profiles of the

mixture of MG16:0 and MG18:0 for $\alpha$ - and $\beta$-type crystals. The endothermic peaks on DSC 
191 reaction. The liquidus temperature was determined from the endothermic peak maximum temperature for each mixture. Because $\beta$-type MG crystal has a higher melting point than that of $\alpha$-type, the liquidus temperatures of $\beta$-type crystal were sifted to higher temperatures than

194 those of $\alpha$-type. The liquidus temperatures of $\alpha$ - and $\beta$-type crystals are shown by solid circles in

196 Figures 2 and 3, respectively, for various binary mixtures of MGs. Each measurement for

$197 \alpha$-type crystal was conducted twice and the first result was chosen; the absolute deviation

198 between the first and second was within $1.3{ }^{\circ} \mathrm{C}$ for any mixtures studied. The $\beta$-type crystal was measured once because the sample preparation took four weeks to ensure the transition 200 into $\beta$-type.

We can obtain the liquidus curves of the binary MGs by connecting these points. The experimental liquidus curves have complex shapes, although we previously reported 203 (Yoshidomi et al., 2017) that binary mixtures of a MG and a FAME give simple, smooth 204 curves. These results imply that the solidification behaviors of MG/MG and MG/FAME mixtures are different. We used the three thermodynamic models described in the previous section to obtain theoretical liquidus curves and compared them with the experimental curves. The theoretical liquidus curves obtained with the non-solid-solution model are shown by dashed-dotted lines in Figures 2 and 3. The model gives v-shaped curves; these 
correspond to eutectic systems, which are widely found in lipid mixtures (Maximo et al.,

211 2014). The theoretical curves obtained with the solid-solution model are shown by dashed

212 lines. These monotonically increasing curves correspond to solid-solution systems, which are

213 frequently found in binary systems composed of similar elements.

214 Figure 2 shows that the behavior of the $\alpha$-type crystals depends on the pair of MGs.

215 In the case of the MG12:0/MG18:0 mixture (Figure 2a), because of the difference between

216 the carbon chain lengths $(\Delta C=6)$, the experimental liquidus temperatures are close to those

217 obtained with the non-solid-solution model. In contrast, the MG16:0/MG18:0 pair (Figure 2c;

$218 \Delta \mathrm{C}=2$ ) conforms to the solid-solution model. These results suggest that a large difference

219 between the carbon chain lengths leads to independent solidification of the individual MGs,

whereas similar MGs can form a solid solution. Such a tendency was reported by Maruyama

et al. for binary systems of MGs (Maruyama et al, 1978). The behavior of the

MG12:0/MG16:0 pair (Figure 2b; $\Delta \mathrm{C}=4$ ) is intermediate between those indicated by the two

models.

Figure 3 shows that for $\beta$-type crystals, the experimental liquidus curves are close to

those obtained with the non-solid-solution model for all pairs, although there are some

deviations. The reason for the difference between the behaviors of the $\alpha$ and $\beta$ crystals 
229 (Maruyama et al., 1971), therefore MGs with shorter chains will independently change to the

$230 \beta$ form earlier than the those with longer chains and the solid solution will be disrupted

231 during the crystal transition.

The results obtained with the two models based on the solid-liquid equilibrium do not fit the complex shapes of the liquidus curves well. The experimental curves have

234 irregularities, with multiple upward convex lines. We therefore used the compound formation model, which is derived from the reaction equilibrium. The results obtained with this model are shown by solid lines in Figures 2 and 3. These results clearly fit the experimental liquidus curves well. We will use Figure 3c, which is the simplest case, to explain the fitting procedure. We first divided the experimental liquidus curve into three regions (I, II, and III). In regions I and III, the compound formation model exactly matches the non-solid-solution model. This means that only MG16:0 solidifies in region I $\left(v_{1}=1, v_{2}=0\right)$ and only MG18:0 solidifies in

242 region III $\left(v_{1}=0, v_{2}=1\right)$. On the basis of this assumption, the reaction equilibrium constant

$243 K_{\mathrm{a}}$ for each region is $\gamma_{1} x_{1}$ (region I) or $\gamma_{2} \mathrm{X}_{2}$ (region III), from equation (6). If the melting

244 point $T_{\mathrm{m}, i}$ of the MG is chosen as the reference temperature $T_{\text {ref, }}$, the compound formation model, via equations (6) and (7), becomes identical to equation (3) for the non-solid-solution special case. 

as the average of the fusion enthalpies weighted by the stoichiometric numbers, as follows:

$$
\Delta H_{\mathrm{ref}}=\frac{v_{1} \Delta H_{m, 1}+v_{2} \Delta H_{m, 2}}{v_{1}+v_{2}}
$$

254 When $v_{1}=3.63$ and $v_{2}=2.25$, the calculated curve fits the experimental plots well, as shown

255 in Figure 3c. For all cases in Figures 2 and 3, we counted the number of upward convex lines

256 to divide the curves into regions, and then fitting was performed independently for each

257 region in the same way. The obtained parameters are summarized in Table 2. Although we are

258 not certain whether or not the obtained stoichiometric numbers reflect the real world, it can

259 be said that the compound formation model can describe the complex solidification behaviors of MGs. hydroxyl groups, which are involved in hydrogen bonding between MGs. Such strong intermolecular interactions allow easy formation of associated molecules, which can be distinguished by X-ray diffraction (Etter, 1990). Such compound-forming systems have also 
267

\section{Multi-component mixtures}

The compound formation model was applied to surrogate biodiesel fuels, namely multi-component mixtures that consisted of MGs and FAMEs. A pair of MGs (1:1 by weight) was added to a mixture of FAME12:0, FAME16:0, and FAME18:1 (65:24:11 by weight) at various MG contents. The liquidus temperatures of the mixtures were determined by DSC, via two methods; the results are shown in Figure 4 by open and solid circles, respectively. We used MG contents higher than $2 \mathrm{wt} \%$ because at low contents the MG endothermic peaks in the DSC curves were too weak. Although such high MG contents are rather far from those in real biodiesel, we performed these experiments to investigate the potential of the model.

First, we determined the liquidus temperatures, which are shown by open circles in Figure 4, by using the method described in the subsection of analytical method for $\alpha$-type MGs, in which the sample was immediately reheated after the first exothermic peak was detected on cooling. However, sudden changes in the liquidus temperature can be observed, especially in Figure 4a. This could be caused by the crystal transition from $\alpha$ to $\beta^{\prime}$ or $\beta$, because the transition time tends to become shorter in the presence of a solvent. FAMEs can act as a solvent in this case, therefore the MGs sometimes change to the $\beta^{\prime}$ or $\beta$ type. Determination of the liquidus temperature for $\alpha$-type MGs in multi-component mixtures is therefore difficult.

We therefore modified the DSC method and examined the sample after transition by 
286 allowing an adequate transition time. For this purpose, the sample was cooled to $-20{ }^{\circ} \mathrm{C}$ and

287 then DSC was performed at a heating rate of $3{ }^{\circ} \mathrm{C} / \mathrm{min}$. The liquidus temperatures obtained by

288 this method are shown as solid circles in Figure 4. In contrast to the previous results, the

289 liquidus temperatures give monotonous curves. This method enabled us to obtain consistent

290 liquidus curves for $\beta^{\prime}$ - or $\beta$-type MGs, although the crystal type was not specified in this

291 study.

For calculations using the compound formation model, $T_{\text {ref }}$ was set at the highest

293 liquidus point among the experimental data. Although the type of crystal was not identified,

294 the enthalpies of fusion for the $\beta$ type shown in Table 1 were used as tentative values for the

295 calculation. The crystal type is not critical for testing the applicability of the model. The

296 parameters $v_{1}$ and $v_{2}$ were determined by data fitting to be 0.00 and 1.19 for (a), 0.00 and

2971.27 for (b), and 0.00 and 0.87 for (c), in Figure 4. The fitting results, which are represented

298 by solid lines, show that the compound formation model works well for predicting the

299 experimental liquidus curves. However, the values of $v_{1}$ and $v_{2}$ obtained by the model will not

always reflect the actual stoichiometric numbers of the solid compounds, because these are

just the results of data fittings.

The excellent matching of the compound formation model with the experimental 
305 Yoshidomi et al., 2017; Sugami et al., 2017), our ultimate purpose was to establish a non-empirical formula for predicting the behaviors of any biodiesel and blends with fossil mixtures. Although we successfully described the complex liquidus curves by using the compound formation model, the parameters obtained will be useless for other cases because the parameters will change if a different chemical component is used. used to predict biodiesel CFPs. This means that we can develop a formula for predicting the CFPs of biodiesels derived from a feedstock as a function of the MG content by data fitting,

314 as in Figure 4, because the fatty acid composition is almost the same for a given type of feedstock.

\section{Concluding remarks}

investigate their interactions. Three thermodynamic models were applied to the obtained

results. The difference between the MG carbon chain lengths $(\Delta C)$ affected the liquidus curve 
324 solid-solution model, in which different MGs form a continuous solid solution.

325 These two models based on the solid-liquid equilibrium did not exactly fit the complicated liquidus curves of binary MGs. Only the compound formation model, which is

327 derived from the reaction equilibrium, can describe the complicated behaviors of binary MGs.

328 This implies that the different MGs form a solid compound via intermolecular hydrogen

329 bonding. It was therefore concluded that the compound formation model is appropriate for describing the solidification behaviors of MGs.

FAMEs. The results show that the model represents the liquidus curves well. However, the experimental data. The parameters will change depending on the chemical composition, therefore obtaining general predictions that apply to all cases is difficult. This model only works for biodiesel from known feedstocks. As a next step, we will apply this model to biodiesel fuels derived from various plant oils and establish a prediction formula for each 339 feedstock.

\section{Conflict of interest}

342 The authors declare that they have no conflict of interest. 
344

345

346

\section{References}

Chupka, G.M., Yanowitz, J., Chiu, G., Alleman T.L., \& McCormick, R.L. (2011). Effect of saturated monoglyceride polymorphism on low-temperature performance of biodiesel. Energy Fuels, 25:398-405.

Chupka, G.M., Fouts, L., Lennon, J.A., Alleman, T.L., Daniels, D.A., \& McCormick, R.L. (2014). Saturated monoglyceride effects on low-temperature performance of biodiesel blends. Fuel Process Technol, 118:302-309.

Committee for Standardization Automotive Fuels. (2008). Fatty acid methyl esters (FAME) for biodiesel engines - Requirements and test methods (EN14214). Brussels: European Committee for Standardization (CEN).

Coutinho, J.A.P., Gonçalves, M., Pratas, M.J., Batista, M.L.S., Fernandes, V.F.S., Pauly, J., \& Daridon, J.L. (2010). Measurement and modeling of biodiesel cold-flow properties. Energy and Fuels, 24:2667-2674.

Dunn, R.O., \& Bagby, M.O. (1995). Low-temperature properties of triglyceride-based diesel fuels: Transesterified methyl esters and petroleum middle distillate/ester blends. J Am Oil Chem Soc, 72:895-904.

Dunn, R. (2010). Cold Weather Properties and Performance of Biodiesel. In: The Biodiesel Handbook, 2nd ed. Illinois: AOCS Press.

Engström, L. (1992). Triglyceride systems forming molecular compounds. Eur J Lipid Sci 
Etter, M.C. (1990). Encoding and decoding hydrogen-bond patterns of organic compounds.

Fischer, E., Bergmann, M., \& Barwind, H. (1920). Neue synthese von a-monoglyceriden.

Gmehling, J., Li, J., \& Schiller, M. (1993). A modified UNIFAC model. 2. Present parameter

Imahara, H., Minami, E., \& Saka, S. (2006). Thermodynamic study on cloud point of biodiesel with its fatty acid composition. Fuel, 85:1666-1670.

Knothe, G. (2005). Dependence of biodiesel fuel properties on the structure of fatty acid alkyl esters. Fuel Process Technol, 86:1059-1070.

Knothe, G., \& Dunn, R.O. (2009). A comprehensive evaluation of the melting points of fatty acids and esters determined by differential scanning calorimetry. J Am Oil Chem Soc, 86:843-856.

Lopes, J.C.A., Boros, L., Kráhenbúhl, M.A., Meirelles, A.J.A, Daridon, J.L., Pauly, J., Marrucho, I.M., \& Coutinho, J.A.P. (2008). Prediction of cloud points of biodiesel. 
Lutton, E.S., \& Jackson, F.L. (1967). Binary systems with monoglycerides. J Am Oil Chem Soc, 44:357-358.

Malkin, T., \& Shurbagy, M.R.E. (1936). An x-ray and thermal examination of the glycerides.

Maruyama, T., Niiya, I., Imamura, M., Okada, M., Matsumoto, T., Horisawa, M., \& Matsumoto, T. (1971). Study on polymorphism of monoglyceride. I. Transition of crystal modification of 1-monolaurin, 1-monomyristin, 1-monopalmitin, and 1-monostearin. J Japan Oil Chem Soc, 20:11-18. (in Japanese)

Maruyama, T., Niiya, I., Imamura, M., Okada, M., \& Matsumoto, T. (1973). Study on polymorphism of monoglyceride. II. Thermodynamic considerations on transition. J Japan Oil Chem Soc, 22:19-22. (in Japanese)

Maruyama, T., Niiya, I., Okada, M., \& Matsumoto, T. (1979). Studies on polymorphism of monoglycerides. VIII. Phase behavior of binary monoglycerides systems. J Japan Oil Chem Soc, 28:26-31. (in Japanese) demands in the solid-liquid equilibrium of lipidic mixtures. RSC Adv, 4:31840-31850. 
Smith, J.M., Van Ness, H.C., \& Abbott, M.M. (2005). Introduction to chemical engineering thermodynamics, 7th ed. New York: McGraw-Hill Education.

Sugami, Y., Yoshidomi, S., Minami, E., Shisa, N., Hayashi, H., \& Saka, S. (2017). The effect of monoglyceride polymorphism on cold-flow properties of biodiesel model fuel. J Am

407 Tang, H., Salley, S.O., \& Ng, K.Y.S. (2008). Fuel properties and precipitate formation at low temperature in soy-, cottonseed-, and poultry fat-based biodiesel blends. Fuel, 87:30063017.

Tumakaka, F., Prikhodko, I.V., \& Sadowski, G. (2007). Modeling of solid-liquid equilibria for systems with solid-complex phase formation. Fluid Phase Equilib, 260:98-104. solid-liquid equilibrium of fatty acid methyl ester and monoacylglycerol mixtures as biodiesel model fuels. J Am Oil Chem Soc, 94:1087-1094. 


\section{List of Tables}

417 Table 1 Thermodynamic properties of MGs

418

419 Table 2 Parameters obtained by using compound formation model for various binary

420 mixtures of MGs and crystalline forms

421 


\section{List of Figures}

423 Fig. 1 DSC profiles of binary mixtures of MG16:0 and MG18:0 for $\alpha$-type (a) and $\beta$-type (b)

424 crystals. ( $x_{1}$ : mole fraction of MG18:0)

425

426 Fig. 2 Experimental liquidus temperatures for various binary mixtures of $\alpha$-type MGs and

427 theoretical curves obtained by using the non-solid-solution, solid-solution, and compound

428 formation models

429

430 Fig. 3 Experimental liquidus temperatures for various binary mixtures of $\beta$-type MGs and

431 theoretical curves obtained by using non-solid-solution, solid-solution, and compound 432 formation models

434 Fig. 4 Experimental liquidus temperatures for surrogate biodiesel fuels determined by the

435 method used for $\alpha$-type MGs (open circles) and modified method (solid circles), along with 436 theoretical curves obtained by using compound formation model (solid lines) 
Table 1 Thermodynamic properties of monoglycerides

\begin{tabular}{|c|c|c|c|c|c|c|c|c|c|}
\hline \multirow{2}{*}{$\begin{array}{l}\text { Component and } \\
\text { type of crystal }\end{array}$} & & \multirow{2}{*}{$\begin{array}{l}\text { Melting point, } \\
{ }^{\circ} \mathrm{C}\end{array}$} & \multirow{2}{*}{$\begin{array}{l}\text { Enthalpy of } \\
\text { fusion, } \mathrm{kJ} / \mathrm{mol}\end{array}$} & \multicolumn{6}{|c|}{ Number of UNIFAC functional group } \\
\hline & & & & $\mathrm{CH}_{3}$ & $\mathrm{CH}_{2}$ & $\mathrm{CH}$ & $\mathrm{OH}(\mathrm{p})$ & $\mathrm{OH}(\mathrm{s})$ & $\mathrm{CH}_{2} \mathrm{COO}$ \\
\hline MG12:0 & $\alpha$ & 44.4 & 22.4 & \multirow{2}{*}{1} & \multirow{2}{*}{11} & \multirow{2}{*}{1} & \multirow{2}{*}{1} & \multirow{2}{*}{1} & \multirow{2}{*}{1} \\
\hline (1-monolaurin) & $\beta$ & 62.1 & 47.5 & & & & & & \\
\hline MG16:0 & $\alpha$ & 64.9 & 34.4 & \multirow{2}{*}{1} & \multirow{2}{*}{15} & \multirow{2}{*}{1} & \multirow{2}{*}{1} & \multirow{2}{*}{1} & \multirow{2}{*}{1} \\
\hline (1-monopalmitin) & $\beta$ & 72.8 & 67.1 & & & & & & \\
\hline MG18:0 & $\alpha$ & 71.6 & 35.1 & \multirow{2}{*}{1} & \multirow{2}{*}{12} & \multirow{2}{*}{1} & \multirow{2}{*}{1} & \multirow{2}{*}{1} & \multirow{2}{*}{1} \\
\hline (1-monostearin) & $\beta$ & 78.9 & 75.2 & & & & & & \\
\hline
\end{tabular}


Table 2 Parameters obtained by using compound formation model for various binary mixtures of MGs and crystalline forms

\begin{tabular}{|c|c|c|c|c|c|c|c|}
\hline \multirow[t]{2}{*}{$\begin{array}{l}\text { Number } \\
\text { of regions }\end{array}$} & \multirow[t]{2}{*}{ Parameters } & \multicolumn{2}{|c|}{$\begin{array}{l}\mathrm{C}_{1}=\text { MG12:0 } \\
\mathrm{C}_{2}=\text { MG18:0 }\end{array}$} & \multicolumn{2}{|c|}{$\begin{array}{l}\mathrm{C}_{1}=\text { MG12:0 } \\
\mathrm{C}_{2}=\text { MG16:0 }\end{array}$} & \multicolumn{2}{|c|}{$\begin{array}{l}\mathrm{C}_{1}=\text { MG16:0 } \\
\mathrm{C}_{2}=\text { MG18:0 }\end{array}$} \\
\hline & & $\alpha$ & $\beta$ & $\alpha$ & $\beta$ & $\alpha$ & $\beta$ \\
\hline & $T_{\text {ref, }}{ }^{\circ} \mathrm{C}$ & 44.4 & 62.1 & 44.4 & 62.1 & 64.9 & 72.8 \\
\hline \multirow[t]{3}{*}{1} & $v_{1}$ & 1.00 & 1.00 & 1.00 & 1.00 & 1.00 & 1.00 \\
\hline & $v_{2}$ & 0.00 & 0.00 & 0.00 & 0.00 & 0.00 & 0.00 \\
\hline & $T_{\text {ref, }}{ }^{\circ} \mathrm{C}$ & 46.6 & 62.9 & 43.9 & 60.7 & 66.8 & 72.4 \\
\hline \multirow[t]{3}{*}{2} & $v_{1}$ & 0.79 & 2.11 & 0.002 & 0.18 & 0.74 & 3.63 \\
\hline & $v_{2}$ & 0.50 & 1.12 & 0.07 & 0.32 & 0.07 & 2.25 \\
\hline & $T_{\text {ref, }}{ }^{\circ} \mathrm{C}$ & 57.4 & 73.7 & 47.2 & 64.2 & 67.5 & 78.9 \\
\hline \multirow[t]{3}{*}{3} & $v_{1}$ & 0.65 & 0.10 & 1.19 & 0.44 & 0.23 & 0.00 \\
\hline & $v_{2}$ & 1.22 & 2.24 & 0.81 & 1.11 & 0.21 & 1.00 \\
\hline & $T_{\text {ref, }}{ }^{\circ} \mathrm{C}$ & 70.6 & 71.6 & 54.4 & 71.7 & 70.9 & - \\
\hline \multirow[t]{3}{*}{4} & $v_{1}$ & 0.18 & 0.00 & 1.44 & 0.20 & 0.09 & - \\
\hline & $v_{2}$ & 1.37 & 1.00 & 2.39 & 3.17 & 0.57 & - \\
\hline & $T_{\text {ref, }}{ }^{\circ} \mathrm{C}$ & 71.6 & - & 64.9 & 72.8 & 71.6 & - \\
\hline \multirow[t]{2}{*}{5} & $v_{1}$ & 0.00 & - & 0.00 & 0.00 & 0.00 & - \\
\hline & $v_{2}$ & 1.00 & - & 1.00 & 1.00 & 1.00 & - \\
\hline
\end{tabular}



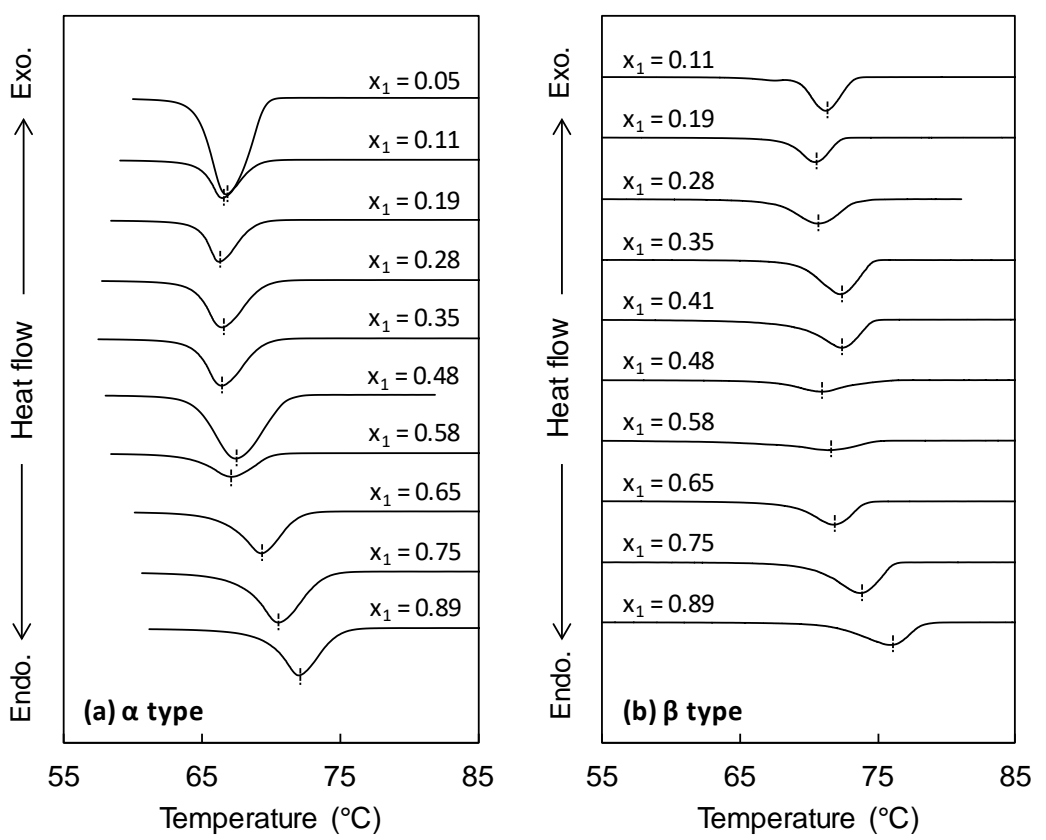

Fig. 1 

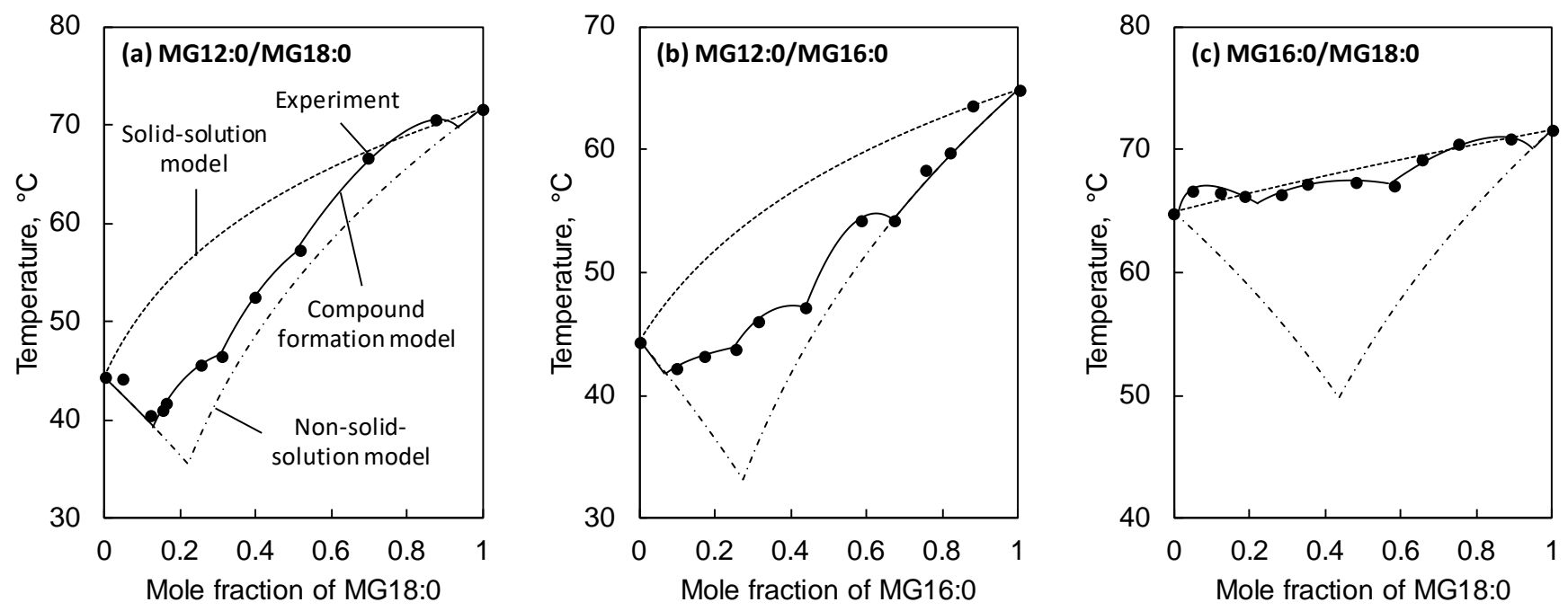

Fig. 2 

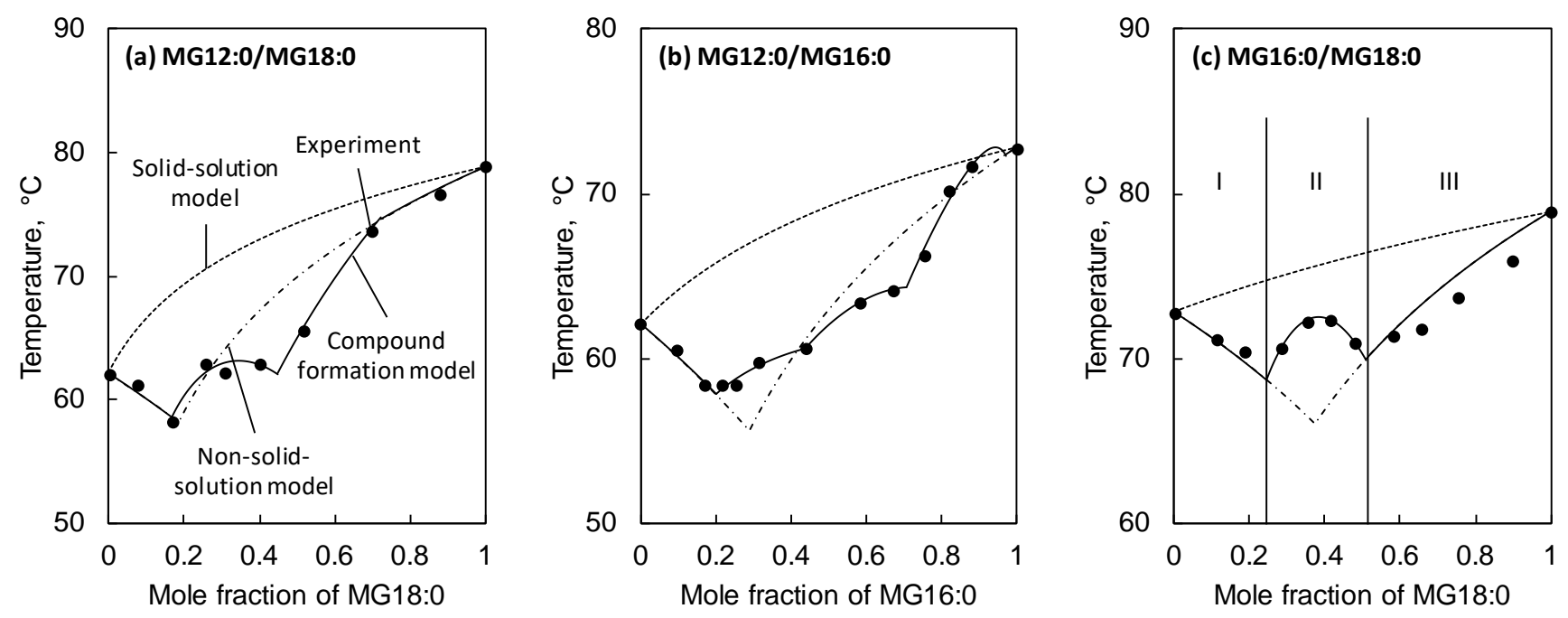

Fig. 3 

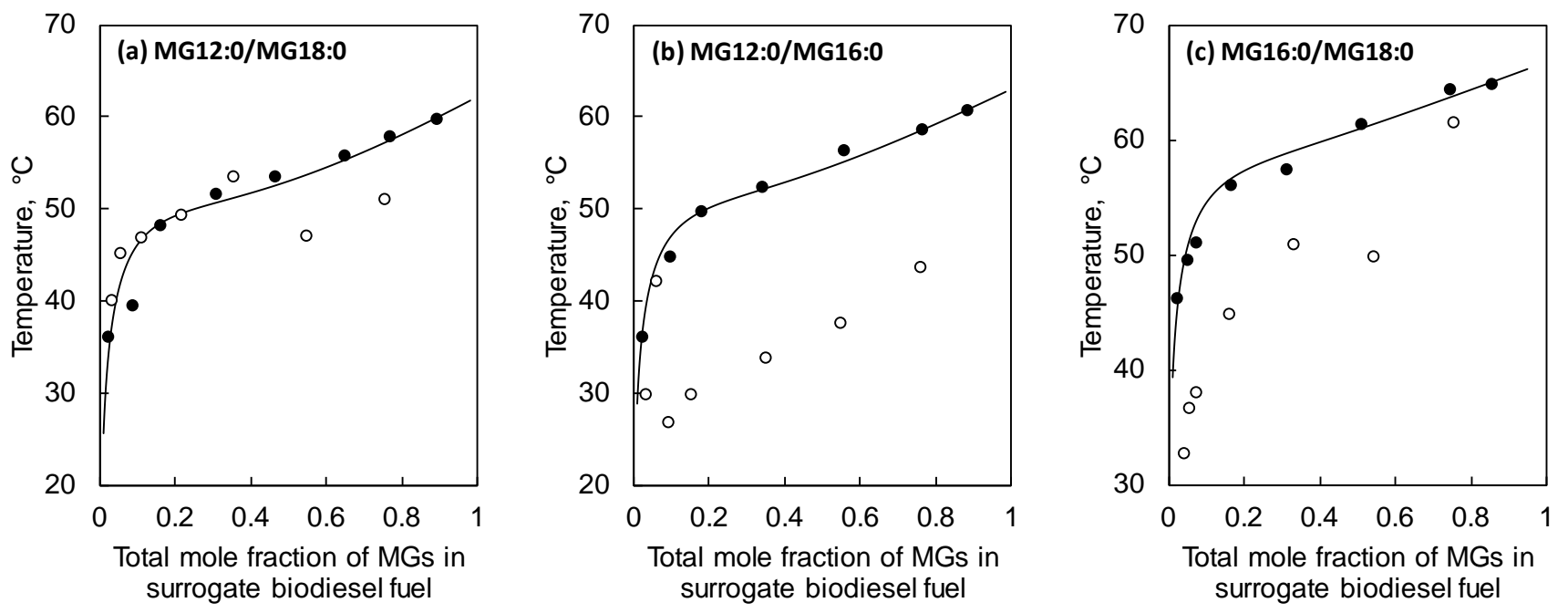

Fig. 4 